\title{
Phase II Study of Second-line Chemotherapy With Paclitaxel, Gemcitabine, and Cisplatin for Advanced Urothelial Carcinoma
}

\author{
MASAHIRO OGAWA ${ }^{1}$, SHINYA YAMAMOTO ${ }^{1}$, TORU INOUE $^{2}$, NOBORU NUMAO ${ }^{1}$, \\ TAKESHI YUASA ${ }^{1}$, HITOSHI MASUDA ${ }^{3}$, IWAO FUKUI ${ }^{1}$ and JUNJI YONESE ${ }^{1}$ \\ ${ }^{1}$ Department of Urology, Cancer Institute Hospital, Japanese Foundation for Cancer Research, Tokyo, Japan; \\ ${ }^{2}$ Department of Urology, Oita University, Oita, Japan; \\ ${ }^{3}$ Department of Urology, National Cancer Center Hospital East, Chiba, Japan
}

\begin{abstract}
Background/Aim: To evaluate the efficacy and toxicity of paclitaxel, gemcitabine, and cisplatin (TGP) as second-line treatment for advanced urothelial carcinoma (UC). Patients and Methods: This study comprised advanced UC progressed after first-line cisplatin-based chemotherapy. Advanced UC was defined as a non-resectable (T4b, any $N$ or any $T$, or N2-3) or metastatic disease. Twenty-one patients were included in this study. TGP was administered every 3 weeks. The primary endpoint was objective response rate (ORR); the secondary end points were progression-free survival (PFS), overall survival $(O S)$, and toxicity. Results: The ORR with TGP was 23.8\%; the median PFS and OS were 4 and 8.4 months, respectively. The primary side effect was myelosuppression. Grade 3-4 neutropenia and thrombocytopenia were observed in $71.4 \%$ and $42.9 \%$, respectively. There were no toxic deaths. Conclusion: TGP is moderately effective and tolerable as second-line chemotherapy for patients with UC.
\end{abstract}

Cisplatin-based combination chemotherapy, such as gemcitabine and cisplatin (GC) or dose-dense methotrexate, vinblastine, adriamycin, and cisplatin (dd-MVAC), is considered the standard first-line regimen for treating patients with advanced urothelial carcinoma (UC) (1-5). Despite a positive response in $40 \%-60 \%$ of patients, disease progression is observed in nearly all patients at a median of approximately 8 months. At our institute (Cancer Institute Hospital, Japanese Foundation of Cancer Research), we use

This article is freely accessible online.

Correspondence to: Masahiro Ogawa, MD, Department of Urology, Cancer Institute Hospital, Japanese Foundation for Cancer Research, 3-8-31 Ariake, Koto-ku, Tokyo 135-8550, Japan. Tel: +81 335200111, Fax: +81 335200141, e-mail: masahiro.ogawa@jfcr.or.jp

Key Words: Advanced urothelial carcinoma, second-line chemotherapy, paclitaxel, gemcitabine, cisplatin.
GC or gemcitabine, etoposide, and cisplatin (GEP) as firstline chemotherapy for treating patients with advanced UC. The median survival rate of patients after GEP chemotherapy was 13.1 months, which is comparable to the outcome after GC chemotherapy (6).

In 2014, we reported the outcome of a phase II GEP trial of first-line chemotherapy for patients with advanced UC (7); the median progression-free survival (PFS) and overall survival (OS) were 8.7 and 16.2 months, respectively. Considering that the median OS after GC chemotherapy was 10-14 months (8), GEP can be an effective first-line treatment for patients with advanced UC. With regard to adverse events, GEP chemotherapy was moderately tolerable with no toxic deaths. However, our impression is that GEP chemotherapy is not as well tolerated as GC chemotherapy in terms of myelosuppression; therefore, we use both GC and GEP as firstline chemotherapy for treating patients with advanced UC.

First-line chemotherapy for advanced UC has already been established; however, second-line treatment for patients in which first-line chemotherapy has failed has not yet been established until pembrolizumab showed up recently, which showed a significantly longer OS and lower rate of treatmentrelated adverse events than second-line chemotherapy for patients with platinum-refractory advanced UC (9).

In 2002, first-line combination chemotherapy of gemcitabine, paclitaxel, and cisplatin (TGP) for advanced UC was reported by Bellmunt et al. (10). They reported that TGP showed a median OS of 15.8 months and did not show significant improvement in PFS or OS compared with GC, but was found to be associated with a significantly better complete response (CR) rate compared with GC (10\% vs. $15 \%, p=0.02$ ) (11). However, the outcome of TGP as secondline chemotherapy for advanced UC remains unreported. To address this issue, we began a pilot study where TGP was administered to patients as second-line chemotherapy when the disease had progressed even after first-line treatment with cisplatin-based combination chemotherapy. This phase II trial uses a lower dose than that reported by Bellmunt et al. (11) 
to avoid severe adverse events. The doses of paclitaxel were set at $60 \mathrm{mg} / \mathrm{m}^{2}$ administered on days 1 and 8 , gemcitabine at $1000 \mathrm{mg} / \mathrm{m}^{2}$ administered on days 1 and 8 , and cisplatin at $50 \mathrm{mg} / \mathrm{m}^{2}$ administered on day 2 . Despite dose reduction, some patients achieved partial response (PR). We therefore, in 2004, initiated a phase II TGP trial as second-line chemotherapy for advanced UC to evaluate its safety and efficacy.

\section{Patients and Methods}

Twenty-one eligible patients between 2004 and 2015 who were histologically or cytologically proven to have UC were included. Patients with pure small-cell carcinoma, adenocarcinoma, squamous cell carcinoma, or a creatinine clearance rate $(\mathrm{CCr})$, calculated by Cockcroft-Gault Formula, of $<50 \mathrm{ml} / \mathrm{min}$ were excluded. All patients were required to have had one round of a cisplatin-based combination chemotherapy and metastasis or locally unresectable lesions (T4b, N2-3, or M1). First-line cisplatin-based combination chemotherapy comprised GC or GEP. Patients who had GC as first-line treatment were administered $1000 \mathrm{mg} / \mathrm{m}^{2}$ of gemcitabine on days 1,8 , and 15 and $70 \mathrm{mg} / \mathrm{m}^{2}$ of cisplatin on day 2 . Patients who had GEP as firstline treatment were administered $60 \mathrm{mg} / \mathrm{m}^{2}$ of etoposide and 20 $\mathrm{mg} / \mathrm{m}^{2}$ of cisplatin on days $1-3$ and $800 \mathrm{mg} / \mathrm{m}^{2}$ of gemcitabine on days 1,8 , and 15 . In both groups, administration of gemcitabine on days 8 and 15 was canceled if patients had an absolute neutrophil count of $<1,000 / \mathrm{ml}$ or a platelet count of $<50,000 / \mathrm{ml}$. If febrile neutropenia, grade 4 thrombocytopenia, grade 3-4 non-hematologic toxicity, or a CCr of 50-60 $\mathrm{ml} / \mathrm{min}$ was encountered, all drug doses were reduced by $20 \%$ for the remaining cycles.

Patients with subsequent recurrent disease following primary radical surgery or radiation were not excluded. The extent of disease just before TGP administration was assessed by computed tomography, magnetic resonance imaging, and a bone scintigraphy if necessary. The primary UC was used as a target lesion only when it was considered measurable. Lymph node (LN) metastasis was confirmed if the enlarged $L N$ was $>1 \mathrm{~cm}$ in diameter. All patients had an Eastern Cooperative Oncology Group performance status of $0-2$ and were expected to live for $>3$ months.

The primary endpoint of this single-cohort phase II study was objective response rate (ORR), and the secondary end points were PFS, OS, and toxicity. The Institutional Review Board of Cancer Institute Hospital, Japanese Foundation of Cancer Research approved this phase II study, and all patients provided written informed consent before being enrolled.

In brief, the TGP regimen comprised $60 \mathrm{mg} / \mathrm{m}^{2}$ of paclitaxel and $1000 \mathrm{mg} / \mathrm{m}^{2}$ of gemcitabine administered on days 1 and 8 and 50 $\mathrm{mg} / \mathrm{m}^{2}$ of cisplatin administered on day 2 . Administration of paclitaxel and gemcitabine was suspended on day 8 for up to 2 days if the patients had an absolute neutrophil count of $<1000 / \mathrm{ml}$ or a platelet count of $<50,000 / \mathrm{ml}$, and it was canceled if there was no recovery.

Evaluations were performed after every two courses of TGP, and responses were classified as CR, PR, stable disease, or progressive disease based on the Response Evaluation Criteria in Solid Tumors v1.1. (12) Responses were recorded only if they were confirmed to have lasted for $>4$ weeks. If a patient had an objective or stable disease response, TGP was continued until disease progression or intolerable toxicity occurred. In case of CR, two additional courses were added if possible.
Table I. Patient characteristics.

\begin{tabular}{lcc}
\hline & No. of patients & $\%$ \\
\hline Age, years & & \\
Median & 63 & \\
Range & $46-81$ & \\
Gender & & \\
Male & 15 & 71.4 \\
Female & 6 & 28.6 \\
ECOG performance status & & \\
0 & 13 & 61.9 \\
1 & 7 & 33.3 \\
2 & 1 & 4.8 \\
Prior regimen & & \\
GEP & 17 & 81 \\
GC & 4 & 19 \\
Primary tumor site & & 52.4 \\
Bladder & 11 & 47.6 \\
Upper urinary tract & 10 & \\
Sites of metastases & & 0 \\
Lung & 5 & 9.5 \\
Liver & 0 & 4.8 \\
Bone & 2 & 71.4 \\
Brain & 1 & 9.5 \\
Soft tissue/lymph nodes & 15 & \\
No metastases & 2 & \\
Multiple sites & & \\
1 site & & \\
2 or more sites & & \\
\hline
\end{tabular}

Survival distributions were calculated using the Kaplan-Meier method. Toxicity was graded according to the National Cancer Institute Common Terminology Criteria for Adverse Events v3.0 guidelines (Common Terminology Criteria for Adverse Events v3.0 (13).

All statistical analysis was performed with JMP software version 13.0 (SAS Institute INC., Cary, NC, USA).

\section{Results}

Patient characteristics are summarized in Table I. The prior tumor site was the bladder in 11 patients and upper urinary tract in 10 patients. Among all patients who underwent one prior chemotherapy regimen, 17 had received GEP and four had received GC. Sixteen patients had one metastasis site, three had two or more sites, and the remaining two were free of any metastasis, but were focally advanced and thought to be non-resectable (cT4b).

The median number of TGP treatment courses was 4 (range $=1-8$ courses) for all patients. Dose reduction was performed according to the criteria above.

An objective response was shown in five patients (23.8\%): 5 had PR (23.8\%) but none had CR. The median PFS was 4 months (range $=4-11$ months) (Figure 1A), and the median OS was 8.4 months (range=3.2-32.3 months) (Figure 1B). 
A

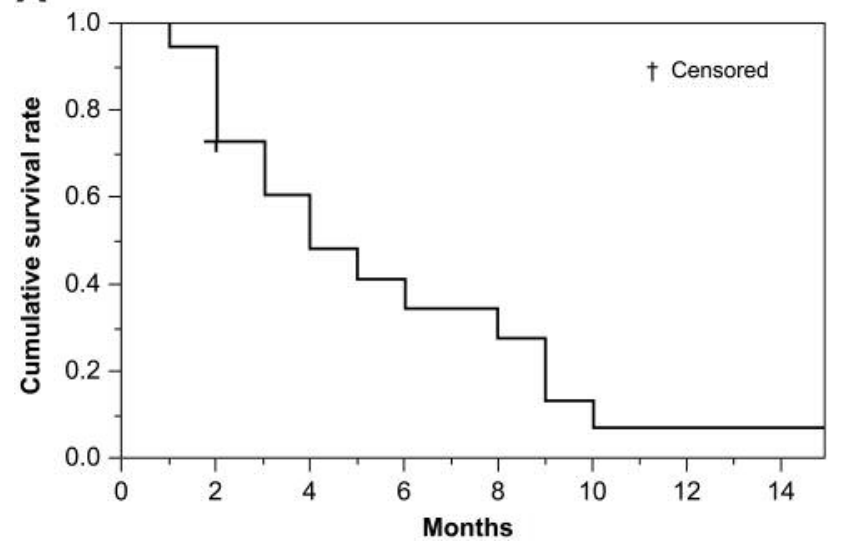

B

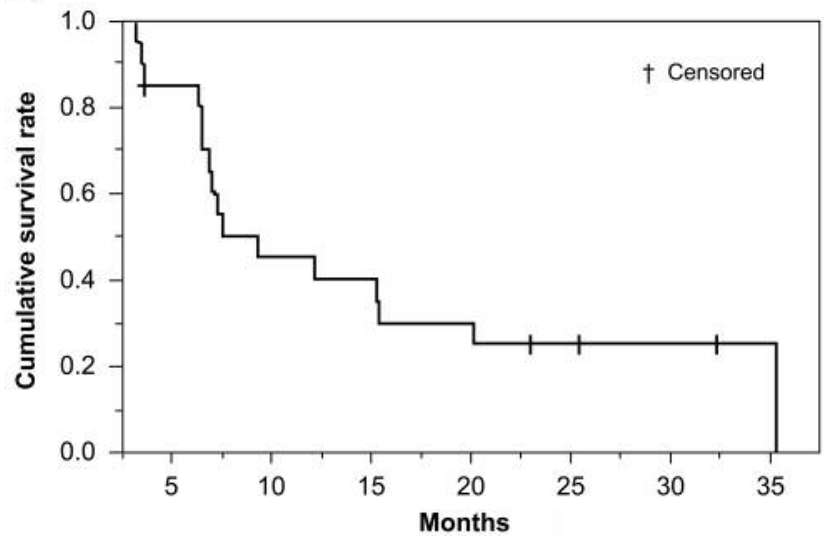

Figure 1. Progression-free survival (A) and overall survival (B) for patients treated with paclitaxel, gemcitabine, and cisplatin.

Adverse events are shown in Table II. The primary toxicity was myelosuppression. Thrombocytopenia was frequently observed (20 patients, $95.2 \%)$; $9(42.9 \%)$ of the 21 patients had grade 3-4 thrombocytopenia; however, no clinical bleeding was encountered. Neutropenia was also common (19 patients, 90.4\%), although febrile neutropenia only occurred in two patients (9.5\%) and neither had severe infections. These patients were treated with granulocytecolony stimulating factor and proper antibiotics and they recovered without any complications. Side effects other than myelopathy were also observed, but grade 3-4 was rarely encountered. There were no toxic deaths.

\section{Discussion}

GC and dose-dense dd-MVAC are already the standard firstline regimens for treating patients with advanced UC. However, second-line chemotherapy for patients whose firstline chemotherapy has failed or whose disease has progressed has not yet been established. Vinflunine, a European Medicines Agency-approved drug, is used for second-line treatment because a randomized trial showed a statistically significant survival benefit (14); however, the use of this drug has not yet been approved in Japan. Single-agent chemotherapy, such as docetaxel (DTX), gemcitabine (GEM), paclitaxel (PTX) or ifosfamide (IFM) was studied as secondline treatment in small phase II trials for patients with UC, but the outcomes were limited with median OS of 9.0 months (DTX), 5.0-13.0 months (GEM), 6.5-7.2 months (PTX), and 5.1-8.0 months (IFM), respectively (15). Among them, singleagent taxane chemotherapy is the most common method for treating patients with advanced UC (16); however, a retrospective study showed that taxane combination chemotherapy was independently and significantly associated with better OS than a single-agent taxane regimen (17).
Table II. Treatment-related adverse events.

\begin{tabular}{lcc}
\hline & Any grade & $\geq$ Grade 3 \\
\hline Neutropenia & $19(90.4 \%)$ & $15(71.4 \%)$ \\
Febrile neutropenia & - & $2(9.5 \%)$ \\
Anemia & $9(42.9 \%)$ & 0 \\
Thrombocytopenia & $20(95.2 \%)$ & $9(42.9 \%)$ \\
Neuropathy & $2(9.5 \%)$ & 0 \\
Muscle/joint pain & $3(14.3 \%)$ & 0 \\
Fatigue & $3(14.3 \%)$ & 0 \\
Drug fever & $3(14.3 \%)$ & 0 \\
Renal dysfunction & $2(9.5 \%)$ & 0 \\
Hepatic dysfunction & $4(19.0 \%)$ & 0 \\
Nausea & $9(42.9 \%)$ & $1(4.8 \%)$ \\
Diarrhea & $2(9.5 \%)$ & 0 \\
Face flush & $2(9.5 \%)$ & 0 \\
Dysgeusia & $2(9.5 \%)$ & 0 \\
\hline
\end{tabular}

To date, the results of several taxane combination regimens (e.g., gemcitabine and paclitaxel chemotherapy) have been reported (18-22). However, the outcomes of these regimens were not satisfactory with an overall response rate of $16 \%-33.4 \%$ and a median OS of 3.7-7.9 months (Table III). The present study also included taxane combination chemotherapy. To the best of our knowledge, this is the first report of a TGP regimen as second-line chemotherapy for patients with advanced UC with prior cisplatin-based combination chemotherapy. The main difference from other second-line taxane combination regimens reported so far is that our TGP regimen includes cisplatin. Cisplatin is a key first-line regimen drug, and the cohort in the present study involved those patients whose disease had progressed after first-line cisplatin-based combination chemotherapy. It may therefore be reasonable to design a second-line regimen 
Table III. Summary of the trials of drug combinations that included paclitaxel.

\begin{tabular}{|c|c|c|c|c|c|c|}
\hline & Combination & No. of patients & ORR & $\mathrm{CR} / \mathrm{PR}(\mathrm{n})$ & mPFS (months) & mOS (months) \\
\hline Terakawa et al. (16) & $\mathrm{PTX}+\mathrm{CBDCA}$ & 16 & $5(31.3 \%)$ & $2 / 3$ & 7.9 & 17.3 \\
\hline Vaishampayan et al. (17) & $\mathrm{PTX}+\mathrm{CBDCA}$ & 44 & $7(16.0 \%)$ & $1 / 6$ & 4.0 & 6.0 \\
\hline Suyama et al. (18) & PTX + GEM & 30 & $10(33.3 \%)$ & $1 / 9$ & 5.5 & 11.3 \\
\hline Kanai et al. (19) & PTX + GEM & 20 & $6(30.0 \%)$ & $1 / 5$ & 4.5 & 11.5 \\
\hline Kaya et al. (20) & PTX + DOX & 36 & $12(33.3 \%)$ & $2 / 10$ & 3.8 & 8.9 \\
\hline Current study & $\mathrm{PTX}+\mathrm{GEM}+\mathrm{CDDP}$ & 21 & $5(23.8 \%)$ & $0 / 5$ & 4.0 & 8.4 \\
\hline
\end{tabular}

CBDCA: Carboplatin; CDDP: cisplatin; CR: complete response; DOX: doxorubicin; GEM: gemcitabine; mPFS: median progression-free survival; mOS: median overall survival; ORR: objective response rate; PR: partial response; PTX: paclitaxel.

comprising drugs other than cisplatin. In our study, the overall response rate was $23.8 \%$, disease control rate was $71.4 \%$, and median PFS was 4 months; these values are within the range of values in previously reported taxanecontaining regimens.

Our results, however, should be carefully interpreted. Urakami et al. (7) showed a relatively higher ORR and longer OS with GEP than with GC as first-line chemotherapy for patients with UC, although their study lacked a randomized comparison of single- versus dual-agent therapy. Considering that $81 \%$ of patients in the present cohort were administered GEP as first-line chemotherapy, a similar OS with TGP for other taxane-containing regimens might be promising, particularly when GEP is administered as firstline chemotherapy. We believe that TGP regimen involves some synergic drug interactions. In fact, paclitaxel has been reported to increase the levels of the active metabolite of gemcitabine (23).

Recently, pembrolizumab, a highly selective, humanized monoclonal $\operatorname{IgG} 4 x$ isotype antibody against PD-1, showed a significantly longer OS and lower rate of treatmentrelated adverse events than second-line chemotherapy for patients with platinum-refractory advanced UC (9), which was a breakthrough for the treatment of patients with advanced UC; however, the compared chemotherapy comprised a single agent of paclitaxel, docetaxel, or vinflunine, which makes the position of taxane combination chemotherapy, such as TGP, as second-line treatment for patients with cisplatin-refractory advanced $\mathrm{UC}$ unclear.

The clinical applicability of TGP regimen was supported by the results of the present study, and while adverse events were observed in many patients, no toxic deaths occurred. The primary toxicity was myelosuppression, and side effects other than myelopathy included neuropathy, muscle/joint pain, fatigue, drug fever, renal dysfunction, hepatic dysfunction, nausea, diarrhea, face flush, and dysgeusia, which were all grade 1-2 and managed well by supportive treatment.
Meluch et al. (24) reported that leukopenia, anemia, and thrombocytopenia were observed in $46 \%, 28 \%$, and $13 \%$ of patients, respectively, following a GP regimen. Febrile neutropenia occurred in $19 \%$ of patients and $2 \%$ experienced treatment-related death. Although not a direct comparison, our clinical impression is that the TGP regimen is not as well tolerated as the GP regimen, but dose modifications and careful treatment indicated sufficient clinical applicability with moderately tolerable toxicity.

The limitations of the present study are the small sample size and absence of a randomized comparison that prevents us from making any definitive conclusions. Although pembrolizumab has been established as a second-line treatment for patients with cisplatin-refractory advanced UC, future phase III randomized studies are needed to determine whether a TGP regimen is truly effective as second-line treatment for patients with advanced UC.

In conclusion, the ORR with the TGP regimen was $23.8 \%$, median PFS was 4 months, and median OS was 8.4 months. The primary toxicity was myelosuppression. Grade 3-4 neutropenia and thrombocytopenia were observed in $71.4 \%$ and $42.9 \%$ of the patients, respectively, but no toxic deaths were reported. The TGP regimen can be moderately effective and tolerable as second-line chemotherapy for patients with UC.

\section{Conflicts of Interest}

All Authors have no conflicts of interest to declare regarding this study.

\section{Authors' Contributions}

Study design: SY; Manuscript writing: MO; Statistical analysis: MO; Coordination of the team and final corrections: JY; Patient's management: MO, TI, NN, TY, SY, IF and JY. All Authors approved the final manuscript.

\section{Acknowledgements}

This research did not receive any specific grant from funding agencies in the public, commercial, or not-for-profit sectors. 


\section{References}

1 Kaufman D, Raghavan D, Carducci M, Levine EG, Murphy B, Aisner J, Kuzel T, Nicol S, Oh W and Stadler W: Phase II trial of gemcitabine plus cisplatin in patients with metastatic urothelial cancer. J Clin Oncol 18(9): 1921-1927, 2000. PMID: 10784633. DOI: 10.1200/JCO.2000.18.9.1921

2 von der Maase H, Sengelov L, Roberts JT, Ricci S, Dogliotti L, Oliver T, Moore MJ, Zimmermann A and Arning M: Long-term survival results of a randomized trial comparing gemcitabine plus cisplatin, with methotrexate, vinblastine, doxorubicin, plus cisplatin in patients with bladder cancer. J Clin Oncol 23(21): 4602-4608, 2005. PMID: 16034041. DOI: 10.1200/JCO.2005.07.757

3 Sternberg CN, De Mulder PH, Schornagel JH, Theodore C, Fossa SD, Van Oosterom AT, Witjes F, Spina M, Van Groeningen CJ, De Balincourt C and Collette L: Randomized phase III trial of high-dose-intensity methotrexate, vinblastine, doxorubicin, and cisplatin (MVAC) chemotherapy and recombinant human granulocyte colony-stimulating factor versus classic MVAC in advanced urothelial tract tumors: European Organization for Research and Treatment of Cancer Protocol no. 30924. J Clin Oncol 19(10): 2638-2646, 2001. PMID: 11352955. DOI: $10.1200 / J C O .2001 .19 .10 .2638$

4 Sternberg CN, De Mulder P, Schornagel JH, Theodore C, Fossa SD, Van Oosterom AT, Witjes JA, Spina M, Van Groeningen CJ, Duclos B and Roberts JT: Seven year update of an EORTC phase III trial of high-dose intensity M-VAC chemotherapy and G-CSF versus classic M-VAC in advanced urothelial tract tumours. Eur J Cancer 42(1): 50-54, 2006. PMID: 16330205. DOI: $10.1016 /$ j.ejca.2005.08.032

5 von der Maase H, Hansen SW, Roberts JT, Dogliotti L, Oliver T, Moore MJ, Bodrogi I, Albers P, Knuth A, Lippert CM and Kerbrat P: Gemcitabine and cisplatin versus methotrexate, vinblastine, doxorubicin, and cisplatin in advanced or metastatic bladder cancer: results of a large, randomized, multinational, multicenter, phase III study. J Clin Oncol 18(17): 3068-3077, 2000. PMID: 11001674. DOI: 10.1200/JCO.2000.18.17.3068

6 Tsukamoto T, Yonese J, Ohkubo Y and Fukui I: Phase I/II study of a combined gemcitabine, etoposide, and cisplatin chemotherapy regimen for metastatic urothelial carcinoma. Cancer 106(11): 2363-2368, 2006. PMID: 16649219. DOI: 10.1002/cncr.21897

7 Urakami S, Fujii Y, Yamamoto S, Yuasa T, Kitsukawa S, Sakura M, Yano A, Saito K, Masuda H, Yonese J, and Fukui I: Phase II trial of first-line chemotherapy with gemcitabine, etoposide, and cisplatin for patients with advanced urothelial carcinoma. Urol Oncol 32(1): 35.e1, 2014. PMID: 23562233. DOI: 10.1016/ j.urolonc.2013.01.007

8 Hainsworth JD, Meluch AA, Litchy S, Schnell FM, Bearden JD, Yost $\mathrm{K}$ and Greco FA: Paclitaxel, carboplatin, and gemcitabine in the treatment of patients with advanced transitional cell carcinoma of the urothelium. Cancer 103(11): 2298-2303, 2005. PMID: 15856431. DOI: $10.1002 /$ cncr.21078

9 Bellmunt J, De Wit R, Vaughn DJ, Fradet Y, Lee JL, Fong L, Vogelzang NJ, Climent MA, Petrylak DP, Choueiri TK and Necchi A: Pembrolizumab as second-line therapy for advanced urothelial carcinoma. N Engl J Med 376(11): 1015-1026, 2017. PMID: 28212060. DOI: 10.1056/NEJMoa1613683

10 Bellmunt J, Albanell J, Paz-Ares L, Climent MA, GonzálezLarriba JL, Carles J, de la Cruz JJ, Guillem V, Díaz-Rubio E, Cortés-Funes $\mathrm{H}$ and Baselga J: Pretreatment prognostic factors for survival in patients with advanced urothelial tumors treated in a Phase I/II trial with paclitaxel, cisplatin, and gemcitabine. Cancer 95(4): 751-757, 2002. PMID: 12209718. DOI: 10.1002/ cncr.10762

11 Bellmunt J, von der Maase H, Mead GM, Skoneczna I, De Santis M, Daugaard G, Boehle A, Chevreau C, Paz-Ares L, Laufman LR and Winquist E: Randomized phase III study comparing paclitaxel/cisplatin/gemcitabine and gemcitabine/ cisplatin in patients with locally advanced or metastatic urothelial cancer without prior systemic therapy: EORTC Intergroup Study 30987. J Clin Oncol 30(10): 1107-1113, 2012. PMID: 22370319. DOI: 10.1200/JCO.2011.38.6979

12 Eisenhauer EA, Therasse P, Bogaerts J, Schwartz LH, Sargent D, Ford R, Dancey J, Arbuck S, Gwyther S, Mooney M and Rubinstein L: New response evaluation criteria in solid tumours: Revised RECIST guideline (version 1.1). Eur J Cancer 45(2): 228247, 2009. PMID: 19097774. DOI: 10.1016/j.ejca.2008.10.026

13 National Cancer Institute: Common Terminology Criteria for Adverse Events (CTCAE) version 3.0. Available at: https://ctep.cancer.gov/protocoldevelopment/electronic_applicats/ docs/ctcaev3.pdf. [Accessed 10 April 2018]

14 Bellmunt J, Théodore C, Demkov T, Komyakov B, Sengelov L, Daugaard G, Caty A, Carles J, Jagiello-Gruszfeld A, Karyakin O and Delgado FM: Phase III trial of vinflunine plus best supportive care compared with best supportive care alone after a platinumcontaining regimen in patients with advanced transitional cell carcinoma of the urothelial tract. J Clin Oncol 27(27): 4454-4461, 2009. PMID: 19687335. DOI: 10.1200/JCO.2008.20.5534

15 Yafi FA, North S and Kassouf W: First- and second-line therapy for metastatic urothelial carcinoma of the bladder. Curr Oncol 18(1): e25-e34, 2011. PMID: 21331269. DOI: 10.3747/co.v18i1.695

16 Sonpavde G and Bellmunt J: Salvage systemic therapy for advanced urothelial carcinoma: on the cusp of a sea change? Oncologist 20(5): 461-463, 2015. PMID: 25845991. DOI: 10.1634/theoncologist.2015-0077

17 Sonpavde G, Pond GR, Choueiri TK, Mullane S, Niegisch G, Albers P, Necchi A, Di Lorenzo G, Buonerba C, Rozzi A and Matsumoto K: Single-agent taxane versus taxane-containing combination chemotherapy as salvage therapy or advanced urothelial carcinoma. Eur Urol 69(4): 634-641, 2016. PMID: 26264159. DOI: 10.1016/j.eururo.2015.07.042

18 Terakawa T, Miyake H, Yokoyama N, Miyazaki A, Tanaka H, Inoue $\mathrm{T}$ and Fujisawa M: Clinical outcome of paclitaxel and carboplatin as second-line chemotherapy for advanced urothelial carcinoma resistant to first-line therapy with gemcitabine and cisplatin. Urol Int 92(2): 180-185, 2014. PMID: 24246751. DOI: $10.1159 / 000354149$

19 Vaishampayan UN, Faulkner JR, Small EJ, Redman BG, Keiser WL, Petrylak DP and Crawford ED: Phase II trial of carboplatin and paclitaxel in cisplatin-pretreated advanced transitional cell carcinoma: a Southwest Oncology Group study. Cancer 104(8): 1627-1632, 2005. PMID: 16138364. DOI: 10.1002/cncr.21370

20 Suyama T, Ueda T, Fukasawa S, Imamura Y, Nakamura K, Miyasaka K, Sazuka T, Egoshi KI, Nihei N, Hamano M and Ichikawa T: Combination of gemcitabine and paclitaxel as second-line chemotherapy for advanced urothelial carcinoma. Jpn J Clin Oncol 39(4): 244-250, 2009. PMID: 19211575. DOI: 10.1093/jjco/hyp003

21 Kanai K, Kikuchi E, Ohigashi T, Miyajima A, Nakagawa K, Nakashima $\mathrm{J}$ and Oya $\mathrm{M}$ : Gemcitabine and paclitaxel 
chemotherapy for advanced urothelial carcinoma in patients who have received prior cisplatin-based chemotherapy. Int J Clin Oncol 13(6): 510-514, 2008. PMID: 19093178. DOI: 10.1007/ s10147-008-0779-x

22 Kaya AO, Coskun U, Ozkan M, Sevinc A, Yilmaz AU, Gumus M, Unal OU, Ozdemir NY, Alici S, Berk V and Degerli H: Paclitaxel plus doxorubicin chemotherapy as second-line therapy in patients with advanced urothelial carcinoma pretreated with platinum plus gemcitabine chemotherapy. Onc Res Treat 35(10): 576-580, 2012. PMID: 23038228. DOI: 10.1159/000342674

23 Shord SS, Faucette SR, Gillenwater HH, Pescatore SL, Hawke RL, Socinski MA and Lindley C: Gemcitabine pharmacokinetics and interaction with paclitaxel in patients with advanced nonsmall-cell lung cancer. Cancer Chemother Pharmacol 51(4): 328 336, 2003. PMID: 12721761. DOI: 10.1007/s00280-002-0560-1
24 Meluch AA, Greco FA, Burris III HA, O’Rourke T, Ortega G, Steis RG, Morrissey LH, Johnson V and Hainsworth JD: Paclitaxel and gemcitabine chemotherapy for advanced transitional-cell carcinoma of the urothelial tract: a phase II trial of the Minnie pearl cancer research network. J Clin Oncol 19(12): 3018-3024, 2001. PMID: 11408496. DOI: 10.1200/JCO.2001.19.12.3018

Received December 18, 2019 Revised January 23, 2020 Accepted January 27, 2020 